\title{
The Effect of Filial Therapy on Somatized Symptoms, Parent-child Interaction and Parents' Empathy with Child Survivors of the 2015 Nepal Earthquake*
}

\author{
Kim, Mi Ra**
}

\begin{abstract}
$<$ Abstract $>$
This study found that child survivors of the 2015 Nepal earthquake have suffered psychological trauma and unstable living conditions in the aftermath. Furthermore, if the children's trauma is neglected, it is likely to be aggravated and become chronic until adulthood. Parent-child relationships are the first relationship that a child has, and parents and children tend to have a close relationship with each other. Through this relationship, the child grows and develops. Filial play therapy has proven to be effective as a psychological intervention program for children in parent-child relationships. This study examined the effects of filial play therapy on the somatization symptoms, parent-child interaction, and empathy ability of child survivors of the Nepal earthquake. As a result, the children's symptoms of somatization were found to have significantly decreased, and it was effective in enhancing parent-child interaction and parental empathy. We also analyzed the process of change through filial play therapy with the parents. As a result, we were able to see the process of change and understand the anxious minds of those parents tried to read their children's minds.
\end{abstract}

Keywords : filial therapy, Nepal earthquake, somatization symptoms, parent-children interaction, empathic abilities

* This paper is part of a 2017 master's thesis at Namseoul University

** Play therapist, Mara Counseling Center for Children and Families (pk01463@naver.com) 
Journal of Symbols \& Sandplay Therapy, Vol.9 No.1.

\section{I . INTRODUCTION}

In April 2015, a devastating earthquake in Nepal killed more than 9,000 people and injured over 10,000. Half of these victims were reported to be less than 18 years of age. Historically, Nepal suffered from many small and big earthquakes (Hangyeore, 2015). Collapsed buildings and fear of additional earthquake displaced more than 50,000 people in the city of Kathmandu alone (Ahn, 2015), and a tent village was formed in the Chuchepati area of the city for these people. Currently there are more than 1,000 people living in 500 tents (Park, 2016).

Living environment in a tent city is extremely poor, especially for child victims. Because people have to share a small, cramped shelter with other families, privacy is not guaranteed and children are exposed to crimes such as sexual assault (The Kyunghyang Shinmun, 2015). And because children have not yet developed cognitively, socially and emotional compared to adults, they do not have enough inner resources to overcome the challenges and recover from the disaster. Therefore, the psychological damage caused by the earthquake is more serious for the children (Lee, 2004). Earthquakes not just bring physical shocks; the resulting psychological distress could continue throughout the entire lifetime of victimized children (Jeong, 2016). Disasters do not have an end; they continue to influence the survivors' lives and mental health (Shim, 2015).

Natural disasters described above bring about material damage and casualties, and child survivors often display their emotional distress through somatic symptoms (Furukawa, Takeuchi, \& Muto, 2015; Oyama, Nakamura, Suda, \& Someya, 2012). In somatization disorders, psychological concerns are manifested through physical symptoms (Escalona, Achilles, Waizkin, \& Yanger, 2004). Somatization also aggravates functional disorders and traumatic stress disorders (Shin, 2000; Chae et al., 2013) and is related with internalization disorders, such as anxiety and depression (Egger et al., 1991).

Compared to adults, children have less social roles and fewer opportunities to express themselves and have not yet developed cognitively. Consequentially, they are relatively unskilled at expressing their feelings verbally and thus their emotional shocks and depression are sometimes expressed through abnormal behaviors (Choi, 2006), and they can also lead to 
secondary problems like anxiety, depression, irritation, sensitivity, anger-out, decreased concentration and aprosexia (Oh et al., 2004). In addition, childhood is a stage where people are still going through both psychological and physical development, and hence they are faced with a set of adaptive demands not only at home with parents but also in school with peers. Thus, without a timely therapeutic intervention, child earthquake survivors will faces difficulties in adaptation, and express frustration, conflict and helplessness (Elkind, 1981). Such emotional problems can be manifested through somatic symptoms.

A timely therapeutic intervention is needed for child earthquake survivors because psychological problems in childhood can easily develop into other psychological disorders. Children with such problems are highly likely to face social and emotional developmental disorders as they will inevitably fail to adapt to society and environment. In addition, somatic symptoms tend to go through alternate phases of improvements and exacerbations and are likely to become chronic by adulthood if left neglected. Thus, somatic symptoms displayed by children deserve substantial attention and research (Song, 2016).

Parents serve as the most critical environment for children. Children grow and develop through the parent-child relationship, the first relationship for everyone, where children and parents influence each other closely (Lee, 2012). In addition, experiences formed through the parent-child relationship greatly affect the formation of a child's basic personality (Seo, 2006). Iacoboni (2008) discovered that mirror neurons allow children to imitate other people's behaviors and to comprehend their intentions, which is based on non-verbal interactions with their parents (Jang, 2017). Empathy is an emotional response of understanding another person's feelings and conditions from their point of view. When you experience empathy, you identify yourself with them in order to understand their feelings and emotions (Eisenberg \& Fabes, 1998). And as described above, children are greatly affected by their parents.

According to WHO's report in 2017, early marriage results in girls leaving school in order to be a housewife, therefore reducing their opportunity to an education, empowerment, employment and self-expression. The stress borne in such situations contributes to high levels of mental health problems, especially depression, in young women of a reproductive age. Their failed experience to solve their psychological problems properly (Kedar, et al., 2017) negatively 
Journal of Symbols \& Sandplay Therapy, Vol.9 No.1.

affects their empathic ability as a parent and hence the parent-child interaction, increasing risks for psychological or physical disorders (Choi, 2014). As such, parents play a crucial role in the formation of a child's psychological difficulties, and it is assumable that the parent's lack of empathy or a negative parent-child interaction will have an adverse effect in a child's development.

Filial therapy is a systemic program developed by Bernard Guerney in 1964. It helps parents increase their sensitivity to their children's desire and emotions so that they can interact with them in a new way. Studies conducted in overseas countries have found that filial therapy increases parents' ability to accept and empathize with their children while reducing children's behavior problems. Filial therapy is a short-term program conducted in a group setting (Jung \& Lee, 2005). It helps parents to assist, understand and empathize with their children's emotions. When the improved empathy ability of parents impacts parent-child relationship in a positive way, it can also bring about positive changes in children's self-expression and behavior problems (Seo, 2006). Empathic understanding is considered to be one of the most important factors that can change parent-child relationship as parents try to feel and think from their children's point of view. (Jung \& Lee, 2005).

There are various types of psychological therapy for parents and children who experienced earthquakes, such as mind training, exposure therapy, cognitive behavioral therapy and meditation. However, this research conducted filial therapy in Nepal on parents who have difficulties in parent-child interaction and empathic ability as a parent, focusing on parent-child relationship.

This research provided six rounds of filial therapy sessions to child survivors of the Nepal earthquake and their parents who are living in a tent city. Through these sessions, the research sought to verify the effectiveness of filial therapy in improving somatic symptoms of child survivors, parent-child interaction and parents' empathic ability and to also explore the process of change during the therapy sessions.

This study sought to answer the following questions:

1. Can filial therapy ease somatic symptoms of child survivors of the Nepal earthquake? 
2. Can filial therapy improve parent-child interaction of child survivors of the Nepal earthquake and their parents?

3. Can filial therapy improve empathic ability of the parents of child survivors of the Nepal earthquake?

4. How parents and child survivors of the Nepal earthquake change over the process of filial therapy?

\section{П. RESEARCH METHOD}

\section{A. Participants}

Participants of this research were parents with children aged between 6 and 12 living in the displacement camp formed in Chuchepati, Kathmandu after the Nepal earthquake. Recruitment was done through leaflets and banners written in the Nepali language. By administering the Patient Health Questionnaire-15 (PHQ-15) in the form of parent-report to those who volunteered, children who scored 10 or more and their parents were selected.

31 parent-child pairs who volunteered to participate with written consent were selected in the beginning. But at the end, 12 pairs were selected for the experimental group and 12 pairs for the control group, excluding three pairs in the experimental group who dropped out,

Table 1. Homogeneity Test Score for Demographic Characteristics

\begin{tabular}{cccc}
\hline & Experimental group & Control group & \multirow{2}{*}{$\mathrm{Z}$} \\
\cline { 2 - 4 } & $\mathrm{M}(\mathrm{SD})$ & $\mathrm{M}(\mathrm{SD})$ & \\
\hline Parent's age & $36.08(6.79)$ & $33.08(7.15)$ & -.80 \\
\hline Parent's academic background & $1.17(0.39)$ & $1.00(0.00)$ & -1.41 \\
\hline Parents' occupation & $0.17(0.39)$ & $0.00(0.00)$ & -1.41 \\
\hline Parent's religion & $1.67(0.65)$ & $1.58(0.51)$ & -.33 \\
\hline Child's age & $9.33(1.83)$ & $7.42(1.68)$ & -1.93 \\
\hline
\end{tabular}

$* p<.05$ 
Journal of Symbols \& Sandplay Therapy, Vol.9 No.1.

two pairs who did not complete the questionnaire and two pairs who refused to conduct a posttest. The results of the homogeneity test for demographic characteristics are specified in Table 1

As shown in Table 1, no significant differences between participants were observed in terms of their age, academic background, occupation and religion, indicating that the two groups were homogenous.

B. Tools

1) Patient Health Questionnare-15 (PHQ-15)

PHQ-15 selects and verifies somatic symptom items by using DSM-IV (Kroenke et al., 2002). PHQ-15 is a 15-item, self-administered questionnaire developed to identify symptoms and severity of somatization of children aged 6 to 17 .

Each item is rated between 0 to 2 , depending on the severity of symptoms: "not bothered at all" $=0$, "bothered a little" $=1$, "bothered a lot" $=2$. The total score is calculated by adding the scores of all items, and the level of severity is evaluated by the total score. Scores from 0 to 4 indicates a minimal severity, 5 to 9 low, 10 to 14 medium and 15-30 high. This study selected children who scored 10 or more and the Cronbach's alpha that indicates the reliability of somatic symptom items was .961 .

\section{2) Parent-Child Interaction (PCI)}

This study used the measures to see the effects of parent interaction on language development in children (Rasha Farouk Safwat, 2014). "Frequency distribution of parent-child interactions" has 29 question items ("never," "sometimes," or "most of the time) and "parents knowledge about language development" has 55 question items ("yes" or "no"). These items are evaluated in the form of parent-report. Total scores of 20 or lower are classified into "low," 21 to 40 "intermediate" and 41 and higher "high." Higher total scores indicate that greater positive change has been made in parent-child interaction and parents have sufficient knowledge in their child's language development. In this study, the Cronbach's alpha for parent child interaction was .920, and parents' knowledge about language development was .788. 


\section{3) Measurement of Empathy in Adult-Child Interaction (MEACI)}

This study used the Measurement of Empathy in Adult-child Interaction (MEACI) developed by Stover, B. Guerney and O'Connell (1971) to measure improvement of parents' empathic ability. MEACI measures the level of receptive communication, permission of children's self-guidance and adults' intervention by three specific adult behavior factors that are confirmed as empathic in adult-child interaction. This study measured the three adult behavior factors based on the video filmed during pre and post sessions at three-minute intervals, during six sessions. Prior to the study, three measurers who majored in child counseling and psychotherapy with a master's degree and three years of experience in play therapy received a training to evaluate 20-minute pre- and post-play sessions through discussions. The conformity degree of the three measurers was .95. Cronbach's alpha for receptive communication was .95. The figure was .93 for permission of children's self-guidance .93 , and .91 for adults' intervention.

\section{Research Procedure}

This study provided a pretest and a posttest to child survivors of the Nepal earthquake and their parents to validate the effectiveness of filial therapy. Parents who scored 10 or higher on PHQ-15 pretest (high-risk group) were selected as participants. There were a total of 24 pairs of participants, 12 in the experimental group and 12 in the control group.

Prior to therapy, the participants were informed about filial therapy sessions, confidentiality, and disclosure of information and filled out a questionnaire and a consent form agreeing to have their sessions videotaped and their pictures photographed. This study was conducted in a way that a researcher and a pre-trained interpreter read the questionnaire to subjects and they answered, due to high illiteracy rates in Nepal. Over the entire course of the study, from interviewing eligible subjects, conducting pretest and posttest to filling out a questionnaire, such method was applied.

12 subjects in the experimental group were divided into two smaller groups of 6 people. Six rounds of 90-minute sessions were provided, twice a week at a requested time, over the course of three weeks in August 2016. This study was conducted in a way that the researcher delivered information about filial therapy through a local interpreter who is fluent in Korean. 
Journal of Symbols \& Sandplay Therapy, Vol.9 No.1.

Through filial therapy, parents of child survivors of the Nepal earthquake learned about play therapy in theory and acquired practical skills for a parent-child interaction. They had a total of three rounds of a 20-minute play session with their children, in a location where they can play with their children in a natural setting with special play materials. After each session, two to three participants would share feedback while watching their videotaped sessions. Whenever participants gathered together, they talked about their play session experience, exchanged feedback and supported each other.

This study is based on the filial therapy model which was introduced by Guerney (1964), modified by Landreth (1991) and adapted to Korean circumstances by Mi-kyung Jang (1998). However, the number of sessions was shortened to 6 rounds, considering that the study was conducted overseas and subjects are the victims of the 2015 Nepal earthquake who are still living in the displacement camps. The program's validity was reviewed by experts and details of the sessions are outlined in Table 2 .

\section{Data Analysis}

Prior to this study, a pretest, semi-structure interviews and training on the purpose of the filial therapy program were conducted through a Nepali coordinator and a Nepali interpreter, in order to collect required data. SPSS Statistics V 24 was used to process quantitative data from the homogeneity test on the demographic characteristics of the experimental group and the control group, and also from the pretest and the posttest. Wilcoxon, a non-parametric statistical hypothesis test, was used to identify the differences between subfactors in each scale. The Cronbach's alpha was calculated for the reliability of parent-child interaction measurement question items. The total process of the filial therapy program, including pre- and post-play sessions, was filmed for the qualitative analysis. The interpreter translated the filmed video, through which the researchers made verbatim notes of the conversations. The notes were analyzed based on parent reports acquired during play sessions and classified into specific areas in order for this study to extract key cases. 
Table 2. Contents of Filial Therapy Program in Each Session

\begin{tabular}{|c|c|}
\hline Session & Details \\
\hline 1 & $\begin{array}{l}\text { I. Wear name tags; Pair up in two, introduce yourselves, and then introduce your partner to the group } \\
\text { П. Overview of the parent-child relationship improvement training } \\
\text { 1. Meaning of play } 2 \text {. Techniques from play therapy } \\
\text { III. Introduction of the basic schedule } \\
\text { IV. Introduction of the group: Introduction of the family and their concerns about the child } \\
\text { V. Reflective listening } \\
\text { ※ Assignment: Identify physical characteristics of the child that were unnoticed before }\end{array}$ \\
\hline 2 & $\begin{array}{l}\text { I. Review the assignments: } 1 \text {. Physical characteristics } \\
\text { I. "Basic Principles of the Parent-Child Relationship Improvement Training" } \\
\text { 1. List of play items } 2 \text {. How to conduct a play session } \\
\text { III. Watch the recorded tape of the therapy session or give a demonstration } \\
\text { IV. Role play in pairs }\end{array}$ \\
\hline 3 & $\begin{array}{l}\text { I. Review the assignments: 1) Share feedbacks on "Reflective Communication" } \\
\text { ПI. Review "Basic Principles of the Parent-Child Relationship Improvement Training" } \\
\text { III. If insufficient, provide another play session training } \\
\text { IV. Role play in pairs }\end{array}$ \\
\hline 4 & $\begin{array}{l}\text { I. Report on how the play session went } \\
\text { ПI. Handout: "Effective Discipline Techniques" } \\
\text { III. Take a look at the videos of last week's parent-child play session and share feedbacks } \\
\text { IV. Role play in pairs } \\
\text { ※ Assignment: Recognize the strong emotions you feel this week }\end{array}$ \\
\hline 5 & $\begin{array}{l}\text { I. Share one emotion the participant felt strongly this past week } \\
\text { П. Handout: "When Setting Boundaries Isn't Effective" } \\
\text { III. Decide who will film her home play session next } \\
\text { IV. Take a look at the videos of last week's parent-child play session } \\
\text { V. Role play in pairs } \\
\text { ※ Assignments: } 1 \text {. Touch 2. Continue having play sessions 3. Practice giving an option to the child }\end{array}$ \\
\hline 6 & $\begin{array}{l}\text { I. Make a report on the play session and what option was provided to the child } \\
\text { П. Handout: "Commonly Encountered Problems" } \\
\text { III. Review the handout "When Setting Boundaries Isn't Effective" and share feedbacks } \\
\text { IV. Take a look at the videos of last week's parent-child play session and share feedbacks } \\
\text { V. Review important rules and precautions } \\
\text { VI. Share their impressions about the filial therapy education } \\
\text { VII. Wrap-up } \\
\text { 1) Share feedbacks on perceived changes in the children and the parents, and their differences } \\
\text { 2) Share feedback on the positive changes and encourage each other }\end{array}$ \\
\hline
\end{tabular}


Journal of Symbols \& Sandplay Therapy, Vol.9 No.1.

\section{Research Findings}

\section{A. Effectiveness of Filial Therapy in Easing Somatic Symptoms of Child Survivors of the Nepal Earthquake}

Prior to filial therapy, the study carried out a nonparametric Wilcoxon signed-rank test to compare pretest-posttest scores for children's somatic symptoms and also the parent-child interaction scores of before and after filial therapy. The results are specified in Table 3 .

As shown in Table 3, the experimental group's somatic symptoms decreased significantly $(Z=-3.09, p<.01)$ compared to the control group. This indicates that filial therapy was effective in reliving the somatic symptoms of child survivors of the Nepal earthquake.

Table 3. Wilcoxon Score for Somatic Symptoms

\begin{tabular}{ccccc}
\hline & & $\begin{array}{c}\text { Pretest } \\
(\mathrm{N}=12)\end{array}$ & $\begin{array}{c}\text { Posttest } \\
(\mathrm{N}=12)\end{array}$ & $\mathrm{Z}$ \\
\cline { 3 - 4 } & & $\mathrm{M}(\mathrm{SD})$ & $\mathrm{M}(\mathrm{SD})$ & \\
\hline \multirow{3}{*}{ Somatic symptoms } & Experimental & $11.00(1.13)$ & $7.00(1.13)$ & $-3.09^{* *}$ \\
\cline { 2 - 5 } & Control & $11.08(1.24)$ & $10.25(0.97)$ & $-1.73^{*}$ \\
\hline
\end{tabular}

${ }^{*} p<.05, \quad{ }^{* *} p<.01$

B. Effectiveness of filial therapy in improving interaction between child survivors of the Nepal earthquake and their parents

PCI measurements were used in the pretest and the posttest to verify the effectiveness of filial therapy in improving parent-child interaction of the child survivors of the Nepal earthquake and their parents. Results are specified in Table 4 and Table 5.

As shown in Table 4, the experimental group showed a significant improvement in parent-child interaction $(Z=-2.98, p<.01)$, compared to the control group. This indicates that 
Table 4. PCl Measurement

\begin{tabular}{|c|c|c|c|c|}
\hline & & $\begin{array}{l}\text { Pretest } \\
(\mathrm{N}=12)\end{array}$ & $\begin{array}{l}\text { Posttest } \\
(\mathrm{N}=12)\end{array}$ & $\mathrm{Z}$ \\
\hline & & $\mathrm{M}(\mathrm{SD})$ & $\mathrm{M}(\mathrm{SD})$ & \\
\hline \multirow{3}{*}{$\begin{array}{l}\text { Parent-child } \\
\text { interaction }\end{array}$} & Experimental & $37.50(12.7)$ & $45.58(9.13)$ & $-2.98^{* *}$ \\
\hline & Control & $35.42(8.36)$ & $36.83(7.74)$ & -1.60 \\
\hline & $\mathrm{Z}$ & -0.35 & & \\
\hline
\end{tabular}

Table 5. Parents' Knowledge About Their Children's Language Development

\begin{tabular}{ccccc}
\hline & & $\begin{array}{c}\text { Pretest } \\
(\mathrm{N}=12)\end{array}$ & $\begin{array}{c}\text { Posttest } \\
(\mathrm{N}=12)\end{array}$ & $\mathrm{Z}$ \\
\cline { 3 - 4 } & & $\mathrm{M}(\mathrm{SD})$ & $\mathrm{M}(\mathrm{SD})$ & \\
\hline \multirow{2}{*}{ Parent's } & Experimental & $12.08(2.43)$ & $18.50(5.05)$ & $-2.95^{* *}$ \\
knowledge & Control & $12.17(2.55)$ & $12.17(2.37)$ & 0.00 \\
\cline { 2 - 4 } & $\mathrm{Z}$ & -0.07 & & \\
${ }^{* * *}{ }_{p<.01}$ & & &
\end{tabular}

filial therapy sessions were effective in improving parent-child interaction of child survivors of the Nepal earthquake and their parents.

In Table 5, the experimental group showed significant improvement in parents' knowledge in their children's language development $(Z=-2.95, p<.01)$, compared to the control group. This indicates that filial therapy sessions were effective in improving parents' knowledge about their children's language development.

Results specified above indicate that filial therapy was effective in improving the parent-child interaction for the child survivors of the Nepal earthquake and their parents.

\section{Effectiveness of Filial Therapy in Improving Parents' Empathy for Their Children}

A pretest-posttest design was used to verify the effectiveness of filial therapy in 
Journal of Symbols \& Sandplay Therapy, Vol.9 No.1.

improving empathy of parents of child survivors of the Nepal earthquake. Prior and posterior to filial therapy, the study carried out a nonparametric Wilcoxon signed-rank test to compare empathy levels between the experimental group and the control group. The results are specified in Table 6:

Table 6. Scores for Measurement of Empathy in Adult-Child Interaction (MEACl)

\begin{tabular}{cccccc}
\hline & & $\mathrm{N}$ & Pretest & Posttest & \multirow{2}{*}{$\mathrm{Z}$} \\
\cline { 4 - 5 } & & & $\mathrm{M}(\mathrm{SD})$ & $\mathrm{M}(\mathrm{SD})$ & \\
\hline $\begin{array}{c}\text { Receptive } \\
\text { communication }\end{array}$ & Experimental & 12 & $21.45(4.02)$ & $14.81(1.57)$ & $-3.06^{* *}$ \\
\hline \multirow{2}{*}{$\begin{array}{c}\text { Permission of } \\
\text { self-guidance }\end{array}$} & Experimental & 12 & $21.97(3.76)$ & $16.31(2.07)$ & $-3.06^{* *}$ \\
\hline \multirow{2}{*}{$\begin{array}{c}\text { Intervention } \\
\text { Control }\end{array}$} & 12 & $22.97(1.97)$ & $22.75(2.12)$ & -0.59 \\
\hline \multirow{2}{*}{ Total score } & Experimental & 12 & $21.39(3.32)$ & $16.00(1.76)$ & $-3.05^{* *}$ \\
& Control & 12 & $23.89(2.25)$ & $23.78(1.83)$ & -0.41 \\
\hline
\end{tabular}

${ }^{*} p<.05, \stackrel{* *}{p} p<.01$

As indicated in Table 6, the experimental group showed statistically significant differences in all measurement items: receptive communication, permission of self-guidance and intervention.

When analyzed based on each subfactor, significant differences were observed in receptive communication and permission of self-guidance $(Z=-3.06, p<.01)$, as well as intervention $(Z=-3.05, \quad p<.01)$. This indicates that filial therapy improved receptive communication, permission of self-guidance and intervention of child survivors' parents. In short, filial therapy improved their interest and participation in their children's play.

As shown in the results above, it can be said that filial therapy was effective in improving empathy of parents of the child survivors of the Nepal earthquake. 


\section{Process of Change During Filial Therapy Sessions}

Below are analyzed findings of how parents of child survivors changed during filial therapy sessions. The entire process of the filial therapy program was filmed and the interpreter translated the parents' comments in the videos, based on which verbatim notes were written.

\section{1) Process of Change in Filial Therapy}

(1) Concerns for the Child

Parents expressed concern for their children's external problems and expressed frustration with their children's anxiety and incomprehensible behavior. Additionally, the parents, living amid inadequate conditions, did not blame their environment and, much like Korean parents, had big aspirations and expectations towards education. They also hoped that their children get sufficient education as the parents themselves lacked it.

\section{(1) Anxiety About the Child}

"I want my child to be educated $\cdots$ My child needs to be educated because we weren't. I am worried about how we are going to educate my child. Also, my child has been complaining about headaches ever since the earthquake ( $1^{\text {st }}$ session, Mother F). My child doesn't study properly. My child doesn't listen to me $\cdots$ My child never listens to me. I would like it if my child studied more $\cdots$ Even if I tell my child there will be plenty of time to play later, my child won't listen to me $\cdots\left(1^{\text {st }}\right.$ session, mother $\left.\mathrm{J}\right)$.

My child keeps spacing out. I always have to tell my child to study ( $1^{\text {st }}$ session, Mother C). My child doesn't even know if she is hungry when she is watching television. I wish my child would study more ( $1^{\text {st }}$ session, Mother D). My child watches a lot of television and plays a lot. My child has a hard time studying $\cdots$ My child does everything but study ( $1^{\text {st }}$ session, Mother E). My child tells me her head hurts $\cdots$ It must because of the earthquake, right? ( $1^{\text {st }}$ session, Mother $\left.\mathrm{K}\right) . "$

(2) Frustrated with the Child's Behavior

"My child says our house isn't safe because there may be another earthquake $\cdots$ my 
Journal of Symbols \& Sandplay Therapy, Vol.9 No.1.

child doesn't speak much ( $1^{\text {st }}$ session, Mother L). After the earthquake, my child gets frequent stomachaches. He also gets startled by thunder ( $1^{\text {st }}$ session, father of $\mathrm{B}$ ). My child has trouble trying to speak. How should I put it; she is a bit strange. I listen when she is trying to speak but I often get frustrated ( $1^{\text {st }}$ session, Mother D). My child barely eats and spaces out often $\cdots$ My child has no problem playing, so I don't know what the problem is ( $1^{\text {st }}$ session, Mother H). My child doesn't eat much, and she doesn't get good grades from school. She barely eats $\cdots$ She will eat a little when I force her, but if I don't, she doesn't care to eat ( $1^{\text {st }}$ session, Mother M)."

(2) Parents' Role as Regulator

By living in the unstable environment of a tent camp, parents and children lacked conversation. Parents reported that they had unilateral communications with their children and scolded them for discipline. They also added that they did not known how to play with their children as they were never taught how to. Parents showed interest in toys, saying that if they had had these toys and this kind of education earlier, they would have spent more time with their children. During play therapy demonstrations, parents were attentive and focused; they lost sight of time, as well as their age, when playing with each other.

\section{(1) Not Knowing How to Play}

"I'm a parent but I do not know how to play with my child (Second session, Mother K). My child has never played with toys like these $\cdots$ Even I didn't get a chance to play with these kinds of toys when I was a kid $\cdots$ (Second session, Mother C). If my child had these toys, she would have a lot of fun. I couldn't teach my children how to play because I've never learned how to play. We used to play with soil when we were young. Nepal doesn't teach kids to play like this, so I've never played with my child (Second session, Mother D). It may be because I don't know how to play with my child, but she enjoys playing with her friends, not me. (Second session, Mother I)." 
(2) Doing as They Were Taught

"After training, I talk to my child with respect $\cdots$ After I began to speak gently, I observed some changes in my child. It made me realize that this is how I should be speaking to her. (Second session, Mother A). I did as I had been taught to do, and my children liked it $\cdots$ (Second session, Mother K). After training, I gave my child more attention and care and she began to speak more with me* I enjoyed spending more time with my child (Second session, Mother E). After training, we came to realize how clueless and foolish we were $\cdots$ We hurt our child a lot (Second session, Mother H). I tried applying what I learned to my child, but I mind went blank and stopped working.. I tried my best to do what the therapist taught me (Second session, Mother A). I found my child talking a lot more once I gave her more attention and care (Second session, Mother E)."

\section{(3) Interaction with the Child}

Because they're used to having many children around, parents were not accustomed to spending time with just one child. They found themselves feeling awkward to spend time with only one child, and sometimes found themselves daydreaming to escape the awkwardness. At the same time, parents found that their changed behavior made children happy. Using caring and loving words towards their children made the children happier, which also made the parents happier. As sessions progressed, parents shared stories about the fun they had while playing with their children, and how their children were began to talk to them more even though they didn't do anything "special." Parents explained that spending time with their children made them lose track of time. Some of them had learned from their own parents that parents ought to give commands and that children should obey, and they unconsciously did the same to their own children instead of listening to what they have to say.

(1) Feeling Awkwardness at the New Parent-Child Interaction

"My child and I have never spent time alone, just the two of us, because I have to take care of all my children (Second session, Mother A). I never received parent education before'. It's hard to alone with just one child, because I keep thinking about the other 
Journal of Symbols \& Sandplay Therapy, Vol.9 No.1.

children (Second session, Mother G). I kept looking at the clock when I was alone with my child $\cdots$ I was told to spend some alone-time with my child, but I kept looking at the clock waiting for play time to end (Fourth session, Mother F). A lot of different thoughts popped up in my mind when spending time alone with my child. It felt like time was crawling by, and I thought thinking about something else would make time go faster. I couldn't wait until my first child came home from school (Fourth session, father of $\mathrm{H}$ ). I found myself thinking about what to do when I was alone with my child. I tried to do as I had learned. It was difficult (Third session, Mother E)."

\section{(2) More Positive Responses}

"I used to order my child to do this and do that. But when I began to speak with affection, my child $\cdots$ hugged me (Third session, Mother D). My child used to tell me that she'd rather play with her friends than with me. But she now says that she enjoys playing with me more (Third session, Mother A). I saw how happy my child became when I respected the things she said. That made me happy as well (Fourth session, Mother A). When I spoke to my child with kind words, my child did the same to me (Fourth session, Mother B). Initially, my child wanted to go outside when I tried to spend time with her. Now, my child says playing with me is fun. She wanted to play more even after play time was over (Fourth session, Mother $\mathrm{H}$ ). If I had this training sooner, I would have known what types of responses were good for my child $\cdots$ When I displayed positive responses, my child liked it. Spending time with her was delightful for me, too (Fourth session, Mother C)."

\section{(4) Increased Comfort in Parenting}

In the early stages of the program, parents only expressed simple feelings about their children, such as "I liked it", "I'm glad", "I'm sad," or "I'm happy." But as sessions progressed, parents could be seen trying their best "to read the child's emotions" or "to reflect the child's emotions." Although they did experience difficulties at first, they gradually began to reflect their children's behavior through various emotional examples. By doing so, they found that their children were willing to engage in more conversations with them and were eager to 
lead the play. Furthermore, towards the end of the program, parents expressed embarrassment and shame, as well as guilt towards their children through new realizations. The "dull" play time slowly became something the parents looked forward to, as confirmed via the parent reports. The parents' once-undifferentiated emotions became increasingly differentiated and complex as the sessions passed, allowing more stories to be told about themselves and their children.

(1) Time of Realization

"I was humiliated when I watched the parent-child play videos. I recalled all the times I shouted at my child and hit him (Fourth session, father of B). I learned what I needed to do when my child is playing (Fourth session, Mother D). I now know how to answer my child's questions (Fourth session, Mother F). After watching the videos, I was embarrassed of all the times I got angry at and scolded my child (Fourth session, Mother M). The videos made me realize a lot of things (Fifth session, Mother C). I learned a lot, but it's still awkward. I realize that I still have a lot to learn (Fifth session, Mother F). When I saw how happy my child was about play time and really looked forward to it, I realized that I need to make more efforts (Sixth session, Mother C). This experience in itself was a big wakeup call (Sixth session, Mother D). I think I now know how important this kind of training is for us (Sixth session, Mother E). I now know what I need to do for my children, thanks to this training (Sixth session, Mother K)."

(2) Reading the Child's Emotions - My Child Happiness is My Happiness

"Just watching my child enjoy playing makes me happy (Fourth session, father of B). Keeping the things I've learned in mind, I knew I had to put it into action for my child (Fourth session, Mother J). It's sad to see that playtime goes by so fast now. My child looks forward to playtime, which makes both of us happy (Fourth session, Mother K). I was very happy and glad. There are no words to express how happy I am. I know what my child is feeling just by looking at her face (Fourth session, Mother L). While playing a game, I "read" my child's feeling to her: "You wanted to beat mommy?" (Fourth session, Mother C). Playtime 
Journal of Symbols \& Sandplay Therapy, Vol.9 No.1.

is extremely fun. I "read" my child's feelings as I have learned. I said things like, "You're upset that you lost" or "Maybe you can win if we try again." When I said those words, my child smiled, and we engaged in the play again (Fifth session, Mother E). My child says that she had fun when playing with me (Fifth session, Mother L). My children have begun to look forward to playtime with me. I now understand that it is through playtime that I can stay close to my children and "read" their feelings (Sixth session, Mother D). My child once held up a human doll to me. I said to my child: "I guess you want to play with this toy, right?" Ever since, my child only plays with that toy (Sixth session, Mother E)."

(3) Respecting the Child's Pace

"Since I began talking to my child with a quiet and soft voice, my child comes to talk to me first (Fifth session, Mother D). All I did was to look at her, but my child's face lit up and she called out 'Mom! Let's make a pretty house together.' I paid attention to her as we played together.. (Fifth session, Mother G). Just by showing positive responses and paying attention, my child had fun and said "I'll try to do better" (Fifth session, Mother H). At whatever pace, fast or slow, my child was playing, I watched her play. And she eventually wanted to play with me (Sixth session, Mother A)."

\section{CONCLUSION AND DISCUSSION}

This study carried out filial therapy on child survivors of the Nepal earthquake and their parents, and analyzed its effectiveness. The study verified the effectiveness of filial therapy in reliving somatic symptoms of child survivors, improving parent-child interaction and raising parents' empathy levels. The process of change that occurred during filial therapy sessions were analyzed qualitatively based on parent reports. The findings of this study were as follows.

First, in the effort to verify whether filial therapy can relive somatic symptoms of the child survivors of the Nepal earthquake, the study discovered that here was a significant improvement in somatic symptoms of children in the experimental group, compared to the control group. Supporting data can be found in following researches: The study of Kim (2016) 
showed that the parent's parenting attitude affects somatic symptoms of adolescents and the study of Jung (2009) indicated that children's emotional variables and parenting variables supporting emotional development influence somatic symptoms of elementary school children.

Second, filial therapy improved parent-child relationship of the experimental group more than that of the control group. This is in line with the research of Kim (2016), which showed that filial therapy increased empathic interaction of a mother for their child and improved relationship between Korean-Chinese mothers and children; Kim et al. (2014), which asserted that the changed parental role of mothers after participating in filial therapy positively affected interaction with their children; and Kim (2015), which discovered that filial therapy improved mother-child interaction of single mothers. The findings of previous studies mentioned above indicated that filial therapy improved parent-child interaction and that parent-child relationship became increasingly stable with less negative interaction as the therapy program proceeded. This validates that filial therapy is an effective program to improve parent-child interaction.

Third, filial therapy significantly improved empathy level of parents in the experimental group, compared to the control group. This is in line with the findings of Yang (2014), whose research showed improvements in empathy of mothers with physical disabilities for their non-disabled children, and of Kim (2016), which showed improvements in empathy ability of parents living in a tent village for the survivors of the Nepal earthquake. Such finding indicate that filial therapy is effective in improving empathy ability of parents in the experimental group, compared to the parents in the control group, by increasing positive communication, expression of interest and acceptance toward their children.

Fourth, the results of analyzing how filial therapy changed parents of the child survivors of the Nepal earthquake identified four representative subjects: "concerns for the child," "parents' role as regulator," "interaction with the child," and "increased comfort in parenting." In the early stage of the program, parents talked about their wishes for their children to be good and smart, rather than their children's wishes. Towards the end, however, the parents tried to understand their children's wishes, rather than always trying to discipline them, and tried to read their emotions. They also talked a lot more about their children. They 
Journal of Symbols \& Sandplay Therapy, Vol.9 No.1.

were enlightened through this process and underwent some transformations.

Prior to the study, eligible subjects were observed and selected through interviews for the purpose of providing psychotherapy to the child survivors of the Nepal earthquake and their parents. Subjects were comprised of children with somatic symptoms and their parents. During filial therapy sessions, improvements and positive changes were induced by psychological intervention.

Studies focusing on psychological intervention for earthquake survivors have been conducted home and abroad, but researches on psychotherapy and parent education for survivors of natural disasters have yet to be carried out. This study is meaningful because it validated the effectiveness of filial therapy in improving somatic symptoms of children, parents' empathy ability and parent-child interaction. In terms of qualitative analysis, this study provides an opportunity to observe changes during filial therapy sessions.

This study validated the effectiveness of filial therapy in relieving somatic symptoms of children and improving parent-child interaction and parents' empathy ability. This study is meaningful because it validated that filial therapy is effective in moderating psychological difficulties of child survivors of the Nepal earthquake and their parents through qualitative analysis of change process during filial therapy sessions. Hopefully, filial therapy can be further utilized to help other child survivors of natural disasters and their parents who undergo psychological difficulties.

Furthermore, this study provided an opportunity to realize the need for psychological intervention for earthquake survivors in Nepal. This study was the first trial to provide psychological counselling to Nepali earthquake survivors, and the importance of psychological intervention for them is not widely known. In this regard, there is a need to promote the significance of providing steady psychotherapy to these survivors. To that end, an organized system to raise experts in psychological and emotional support should be established.

Suggestions for future research efforts based on the limitations of this study are as follows: First, participants of this study were comprised entirely of the 2015 Nepal earthquake survivors living in the displacement camps in the Chuchepati area of Kathmandu, Nepal. This means regional, environmental and cultural characteristics might have affected the results, which 
was possibly further influenced by time and space constraints. Therefore, effectiveness of filial therapy cannot be generalized for other Nepal earthquake survivors. Hence future studies would have to be conducted with various types of participants from a host of regions in order for filial therapy's effectiveness to be universalized.

Second, the number of filial therapy sessions was shortened to six due to environmental constraints despite the fact that more sessions are required for the parents to acquire play skills. Providing one session per day was impossible due to the researcher's short-term stay in Nepal. Hopefully, however, this study laid a foundation for long-term researches to be conducted in relation to Nepal.

Third, there are difficulties to conduct follow-up tests due to various external factors, such as environmental constraints, despite the need to verify the constant effectiveness of filial therapy. In this regard, further researches on the child survivors of the Nepal earthquake and their parents are needed in order to verify whether the effectiveness of filial therapy lasts after the termination of the program. And hopefully INGOs will deploy experts and provide organized support measures in this area, given the severity of psychological and emotional difficulties that the earthquake survivors are facing.

Fourth, the Nepali government should come up with practical measures to better protect children from earthquakes, e.g., strengthening the emergency relief service system and safety education for children and requiring schools to provide safety education by law. Hopefully, the psychotherapy experts will work in Nepal through partnership with universities with manpower and financial support.

Fifth, Nepal lacks the concepts of counseling and psychotherapy when, in fact, there is a great need for counseling, psychotherapy and education. If counseling experts are deployed in schools, psychological support can be provided effectively to the children in need and possibly even to their parents and families.

Despite these limitations, this study is highly meaningful for the following reasons: First, research dealing with the effectiveness of a parent education program on the child survivors of the Nepal earthquake and their parents has yet to be carried out. Second, this study validated the effectiveness of filial therapy in improving somatic symptoms of child 
Journal of Symbols \& Sandplay Therapy, Vol.9 No.1.

earthquake survivors, parent-child interaction and parents' empathy ability. Third, this study provided an opportunity to witness the process of change during filial therapy sessions.

Hopefully, psychotherapy programs, including filial therapy, that compensate for the limitations of this study will be developed, and will provide effective help to child survivors of earthquakes and their parents.

\section{References}

Ahn, Y-H (2015). The Scene of Nepal earthquake. Kwanhun Journal, 135, 184-192.

Chae, J-H, Kang, S-H, Kim, D-H, Park, J-E, Bae, G-Y, Lee, B-C, Heo, Y-J (2013). A Study on development of property status PTSD response manual. Gwangju Trauma Center: Ministry of Health and Welfare.

Choi, G-R (2014). Reliability and validity of the checklist of the korean version revised edition life stress cases: targeting outpatients with anxiety disorder and depressive disorder. Master's Thesis of Hanyang University Graduate School.

Choi, N-H (2006). Post-support for Disaster Victims: Rehabilitation of disaster victims. Korea Crisis Management Papers, 2(2), 3-17.

Egger, H. L., Costello, E. J., Erkanli, A., \& Angold, A. (1991). Somatic complaints and psychopathology in children and adolescents: Stomachaches, musculoskeletal pains, and headaches. Journal of the American Academy of child and Adolescent Psychiatry, 38(7), 852-860.

Eisenberg, N., \& Fabes, R. A. (1998) Proscoial development. In N. Eisenberg (ED.), W. Damon (Series Ed.), Handbook of child psychology: 3, 701-778.

Elkind, D. (1981). The burried child. MA: Addison-Wesley.

Escalona, R., Achilles, G., Waitzkin, H., \& Yager, J. (2004). PTSD and somatization in women treated at a VA primary care clinic. Psychosomatics, 45(4), 291-296.

Furukawa, H., Takeuchi, T., Yano, E., \& Muto, S. (2015). Factors influencing psychological distress after the great east Japan earthquake and tsunami. Journal of Community Psychology, 43(5), 521-526. 
Guerney, B. (1964). Filial therapy: Description and rationale. Journal of Consulting Psychology, 28(4), 303-310.

Han C, Pae CU. (2009). PHQ-15 for measuring the somatic symptoms of psychiatric outpatients. Psychosomatics, 50(6), 580-585.

Hankyoreh (2015). Subsequent earthquakes in Nepal - Japan, The Prelude of the 'ring of fire' big earthquakes. 2015.06.01. http://www.hani.co.kr/arti/science/kistiscience/693681.htm

Iacoboni, M. (2008). Imitation, empathy, and mirror neurons. Annual Review of Psychology, 60, 653-670

Jang, M-K. (1998). The Effects of parent - child relationship enhancement training program using the child-centered play therapy technique. Master's Thesis of Sookmyung Women's University Graduate School.

Jang, M-K. (2017). Analytical Psychological Sand Play Therapy. Hakjisa.

Jeong, G-S (2009). Somatic Symptoms of elementary school children according to emotion-related children and parenting variables. Korean Children's Society, 30(4), 155-171.

Jeong, G-S, Lee, E-H (2005). A Study on the reduction of interpersonal behavioral problems in children' family through parent-child play therapy. Emotion - Education Field Research , 21(4), 111-138.

Jeong, Y-I (2016). The Effects of physical contact development play therapy on the interaction and empathy of parent-child living in Nepal earthquake victim group tent village and the process of relationship change. Master's Thesis of Namseoul University Graduate School.

Kroenke, K., Spitzer, R. L., \& Williams, J. B. (2002). The PHQ-15: Validity of a new measure for evaluating the severity of somatic symptoms. Psychosomatic Medicine, 64(2), 258-266.

Kedar, M., Reuben S., Pawan S., Lonim D., Bhola R. S. (2017). Suicide burden and prevention in Nepal: The need for a national strategy. WHO South-East Asia Journal of Public Health, $6(1), 45-49$.

Kim, D-J, Han Jae-hee (2014). A Study on the change experience of parental role of mothers participating in parent - child play therapy. Journal of Korean Association of Christian Counseling, 25(4), 43-77. 
Journal of Symbols \& Sandplay Therapy, Vol.9 No.1.

Kim, E-Y (2016). The Effects of parenting attitudes on the somatization symptoms of adolescents. Korean Association for Learner-centered Curriculum and Instruction, 16(8), 457-473.

Kim, H-Y (2016). The Effects of the filial therapy on parenting stress of korean-chinese mothers and children's behavior problems and the change process of parent - child relationship. Master's Thesis of Namseoul University Graduate School.

Kim, S-S (2016). The Effects of the filial therapy on children's behavioral problems and empathy ability, interaction of parents living in the Nepal earthquake survivor group tent village. Master's Thesis of Namseoul University Graduate School.

Kim, S-Y (2015). The Effects of the filial therapy on parenting stress of unmarried mothers, child's behavioral problems and mother-child interaction. Master's Thesis of Namseoul University Graduate School.

Kyunghyang Shinmun (2015). Three months after the earthquake, children in Nepal suffering from fear of crime in a temporary tent.

Landreth, G. L. (1991). Play therapy: The art of the relationship. Routledge.

Lee, M-S (2012). The Mediating Effects of empathy and ego-resiliency in the relationship between children's parent - child communication and school adjustment. Master's Thesis of Dong-A University Graduate School.

Lee, Y-J (2004). The Psychological Impact of disaster damage and method of psychological assistance to overcome disaster: focusing on children. Korea Youth Counseling \& Welfare Institute, 12(1), 28-40.

Oh, Y-H, An Chang-il, Oh Gwang-Sup (2004). Differences in clinical aspects according to the history of childhood anxiety disorder and its absence/ presence in patients with adult anxiety disorder. Journal of Korean Psychological Association: Clinical, 23(4), 873-889.

Oyama, M., Nakamura, K., Suda, Y., \& Someya, T. (2012). Social network disruption as a major factor associated with psychological distress 3 years after the 2004 Niigata-Chuetsu earthquake in Japan. Environmental Health and Preventive Medicine, 17(2), 118-123

Park, E-C (2016). 1 year after Nepal earthquake unfinished disaster. Life Live Sisa.

Rasha Farouk Safwat, Aya R. Sheikhany. (2014). Effect of parent interaction on language development in children. The Egyptian Journal of Otolaryngology, 30, 255-263 
Seo, J-Y (2006). The Effects of the filial therapy for enhancing the empathy of father - mother and improving children's behaviorial problems. Master's Thesis of Namseoul University Graduate School.

Shin, H-G (2000). The Effects of negative emotions, alexithymia, awareness of somato-sensory amplification, and somatic attribution on somatization. Journal of Korean Psychological Association: Clinical, 19(1), 17-32.

Shin, H-G (2000). Clients with physical symptoms. Hanyang University College Life Research, 18, $15-36$.

Shim, W-J (2015). Earthquake and border closure. Eventful 2015 in Nepal.

Song, K-A (2016). A Single Case Study of art therapy for children with anxiety and somatization symptoms. Master's Thesis of Dongguk University Graduate School.

Stover, L., Guerney Jr, B. G., \& O'connell, M. (1971). Measurements of acceptance, allowing self-direction, involvement and empathy in adult-child interaction. The Journal of psychology, 77(2), 261-269.

WHO (2017). South-east asia. Suicide in Nepal.

Yang, H-H (2014). The Effects of the filial therapy program on empathy ability of with physical disabilities and depression and self-esteem of non-disabled children. Master's Thesis of Namseoul University Graduate School.

2015. 07.26. retrieved from http://news,khan.co.kr/kh news/khan art view. html artid=20150726



